\title{
THREE DIMENSIONAL FLUID FLOW WITHIN A RECTANGULAR CHANNEL WITH SEVERAL CYLINDRICAL (AND/OR) ELLIPTICAL BLOCKS: LATTICE BOLTZMANN INVESTIGATION
}

\author{
A. BOUTRA ${ }^{1,2, *}$, K. RAGUI ${ }^{1}$, N. LABSI ${ }^{1}$, Y.K. BENKAHLA ${ }^{1}$, R BENNACER \\ ${ }^{1}$ Laboratory of Transport Phenomena, USTHB, Algiers, Algeria. \\ ${ }^{2}$ Ecole Supérieure des Sciences Appliquées d'Alger, Algerie. \\ ${ }^{3}$ LMT - ENS Cachan - CNRS - Paris Saclay University, 94230 Cachan, France
}

\begin{abstract}
Through this paper, we investigate numerically a Three-dimensional laminar flow of an incompressible Newtonian fluid within a rectangular channel; including several adiabatic partitions of a cylindrical (and/or) elliptical shape. To do so, a numerical code based on the Lattice Boltzmann approach is used. In other words, three dimensions D3Q19 model is adopted all based on a cubic Lattice, where each pattern of the latter is characterized by nineteen discrete speeds. Our numerical code has been successfully validated after a wide comparison between the present results and those of the literature. By taking into account the Reynolds number, the partitions' shape impact on the flow fields within the channel is taking all attention and that throughout the time' Streamlines and the velocity profiles. The pressure drop within our channel is also investigated to come out with the best arrangement of these kinds of partitions within.
\end{abstract}

\section{NOMENCLATURE}

a

$\mathrm{a}_{\mathrm{ij}}$

$\mathrm{c}_{\mathrm{s}}$

$f_{\text {eq }}$

$\mathrm{F}_{\text {ext }}$

$f_{i}$

$\mathrm{L}_{\mathrm{x}, \mathrm{y}, \mathrm{z}}$

$\mathrm{m}_{\mathrm{j}}$

P

$\Delta \mathrm{P}$

$\mathrm{Re}$

$\mathrm{S}_{\mathrm{j}}$

$\mathrm{t}$

T

$\mathrm{u}$

V

W

$\mathrm{x}, \mathrm{y}, \mathrm{z}$

$\mathrm{X}, \mathrm{Y}, \mathrm{Z}$

\section{Greek letters}

Coefficient in external forces $(=\mathrm{g} \beta)$

Coefficients in Equation (3)

Sound velocity in the Lattice $\left(c_{s}=1 / \sqrt{3}\right)$

Equilibrium distribution Function

External Force

Distribution Function

Enclosure dimensions, (m)

Moments

Lattice Unit Pressure, lu

Global drop pressure into the Channel

Reynolds number

Relaxation rate

History time, (s).

Temperature, (K)

Horizontal velocity component, $(\mathrm{m} / \mathrm{s})$

Vertical velocity component, $(\mathrm{m} / \mathrm{s})$

Depth velocity component, $(\mathrm{m} / \mathrm{s})$

$\omega_{\mathrm{i}} \quad$ Coefficients of the equilibrium function

$\rho \quad$ Density, $\left(\mathrm{kg} \mathrm{m}^{-3}\right)$

$\varepsilon \quad$ Energy square

$v \quad$ Kinematic viscosity, $\mathrm{m}^{2} \mathrm{~s}^{-1}$

$\Omega \quad$ Collision Operator

\section{Subscripts}

f $\quad$ Fluid

in Entry

\section{INTRODUCTION}

Incompressible Newtonian flow around a cylindrical/elliptical confined in a channel is one of complex problems in computational fluid dynamics (CFD) [1-4]. The fluid motion within such configurations is an important phenomenon regarding the engineering systems. The grasp of such phenomenon in these systems still a critical topic, since the pressure drop remains one of the most technical challenges.

Into an infinite horizontal channel, the fluid flow has received a great attention in recent years [5-8]. To create a secondary movement, and an important mixing of the fluid medium, this configuration has been developed by using baffles and adiabatic partitions sticks to the horizontal walls [9-12].

Even though there have been these numerous investigations, under many boundary conditions, relatively few studies were documented by taking into account the extension of a cylindrical blocks to an elliptic one. As such, this paper presents a comprehensive numerical study of a three-dimensional fluid flow within a rectangular channel containing cylindrical (and/or) elliptical blocks, up in series, to come out at the end with a perfect blocks' arrangement with less global drop pressure for the convenience of practical applications. Note that our numerical investigation is developed using the Lattice Boltzmann approach [13].

\footnotetext{
* Corresponding author: aeknad@yahoo.fr
} 


\section{PROBLEM STATEMENT}

The investigated configuration, shown through Fig. 1 , consists of a three dimensional channel with several adiabatic cylinders (and/or elliptic). The working fluid (which is water), is assumed to be Newtonian, its thermophysical properties are presumed to be constant except the density variation, in the buoyancy term, which follows the Boussinesq approximation [14].

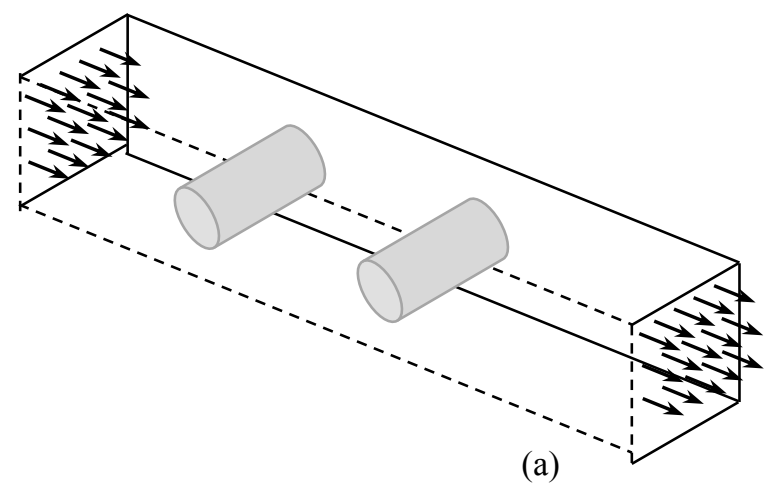

(a)

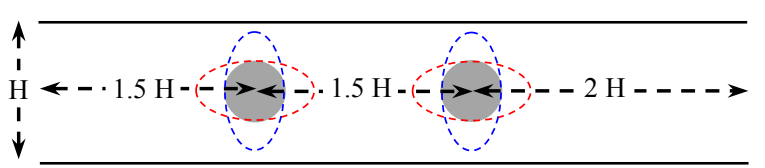

(b)

Fig 1 Simulation domain in 3D (a) and 2D dimension (b).

\section{LATTICE BOLTZMANN APPROACH}

Different from previous numerical investigations; which adopt the finite volume, finite difference or finite element method, the present study uses the Lattice Boltzmann method (LBM) as a solver. The latter has drawn considerable attention in all scientific domains and has matured as an efficient alternative for simulating and modeling complex physical systems[15-16], such as the work of Yang et al. [17] who used a large-eddybased lattice Boltzmann model to look for the cooling efficiency on the surface under constant-temperature or constant-heat-flux condition, and $\mathrm{Yu}$ et al. [18] who discussed the D3Q19 MRT-LBE model in conjunction with the Smagorinsky subgrid closure model tested in the turbulent square jet flow case, to name but a few.

Regarding the Lattice Boltzmann equation for the Newtonian fluid, we considered a nineteen-velocity model of a three-dimensional lattice so-called D3Q19 model [15] (see Appendix A).

For the adopted dynamic model, two successive phases are taken into account; starting with the first one which expresses the propagation of particles from nodes to their neighbors, and continuous with the second one, so-called as the collision, where particles on the same lattice redistribute and relax into their quasi-equilibrium. The particles distribution equation can be expressed as follows: $\frac{\partial \overrightarrow{\mathrm{f}}}{\partial \mathrm{t}}+\overrightarrow{\mathrm{c}} \nabla \overrightarrow{\mathrm{f}}=\left(\frac{\partial \overrightarrow{\mathrm{f}}}{\partial \mathrm{t}}\right)_{\text {scat }}$

where $f(x, c, t)$ is the distribution function depending on the particle velocity (c) at a location (x) and a time $(\mathrm{t})$. The right side term of particles distribution equation displays the diffusion process when the new equilibrium distribution is rebuilt after the collision [19-23].

Function of the location ( $x$ ) and the time (t), the fluid shape can be defined as particles populations vector, noted as $f_{i}$, where $i=0,1,2, \ldots, 18$. Thus, the discrete distribution equation can be given as:

$\mathrm{f}_{\mathrm{i}}\left(\mathrm{x}+\mathrm{c}_{\mathrm{i}} \Delta \mathrm{t}, \mathrm{t}+\Delta \mathrm{t}\right)=\mathrm{f}_{\mathrm{i}}(\mathrm{x}, \mathrm{t})+(\Omega \mathrm{f})_{\mathrm{i}}$

where $\left(f_{i}\right)$ is the space vector based on the discrete velocity set and $\Omega$ is the collision operator. Noted that a primary discrete velocity sets will be created then from the set of 18 vectors pointing from the origin to the above neighbors and the zero vector $(0,0,0)$.

The space vector, $f_{i}$, is constructed using the moment of the last. The relationship between two spaces is defined by means of the below equation, when the coefficient $\mathrm{a}_{\mathrm{ij}}$ is calculated using the particle velocity $c_{i}$.

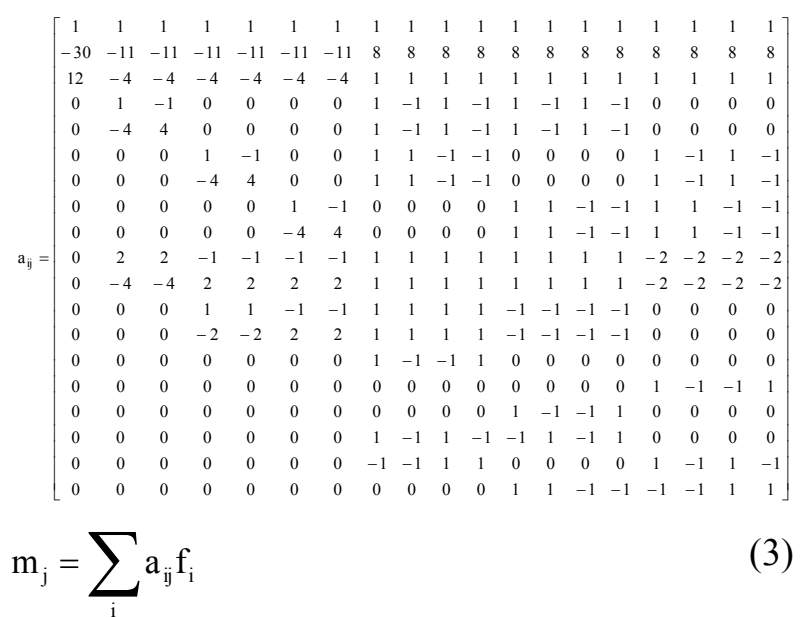

where the corresponding 19 moments $\mathrm{m}_{\mathrm{j}}(0,1,2, . ., 18)$ are: the mass density $\left(m_{0}=\rho\right)$, the kinetic energy independent of the density $\left(\mathrm{m}_{1}=\mathrm{e}\right)$, the kinetic energy square independent of the density and kinetic energy $\left(\mathrm{m}_{2}\right.$ $\left.=\varepsilon=\mathrm{e}^{2}\right)$, the momentums $\left(\mathrm{m}_{3 ; 5 ; 7}=\mathrm{j}_{\mathrm{x} ; \mathrm{y} ; \mathrm{z}}\right)$, the energy flux independent of the mass flux $\left(\mathrm{m}_{6 ; 8 ; 10}=\mathrm{q}_{\mathrm{x} ; \mathrm{y} ; \mathrm{z}}\right)$, and the symmetric traceless viscous stress tensor $\left(m_{9}=3 p_{x x}\right.$, $\mathrm{m}_{11}=\mathrm{p}_{\mathrm{ww}}=\mathrm{p}_{\mathrm{yy}}-\mathrm{p}_{\mathrm{zz}}$, with $\mathrm{p}_{\mathrm{xx}}+\mathrm{p}_{\mathrm{yy}}+\mathrm{p}_{\mathrm{zz}}=0, \mathrm{~m}_{13 ; 4 ; 15}=$ $\left.\mathrm{p}_{\mathrm{xy} ; \mathrm{yz} ; \mathrm{zx}}\right)$.

The two vectors of quadratic order, $\mathrm{m}_{10}$ and $\mathrm{m}_{12}$, have the same symmetry as the diagonal part of the traceless tensor $\mathrm{p}_{\mathrm{ij}}$, while the other three vectors of cubic order are parts of a third rank $\mathrm{m}_{16 ; 17 ; 18}$ tensor, with the symmetry of $j_{k} p_{n m}$. The diagonal collision matrix $S_{i j}$ is given as:

$\mathrm{S}_{\mathrm{ij}}=\left(\begin{array}{l}0, \mathrm{~s}_{1}, \mathrm{~s}_{2}, 0, \mathrm{~s}_{4}, 0, \mathrm{~s}_{4}, 0, \mathrm{~s}_{4}, \mathrm{~s}_{9}, \mathrm{~s}_{10}, \\ \mathrm{~s}_{9}, \mathrm{~s}_{10}, \mathrm{~s}_{13}, \mathrm{~s}_{13}, \mathrm{~s}_{13}, \mathrm{~s}_{16}, \mathrm{~s}_{16}, \mathrm{~s}_{16}\end{array}\right)$ 
Note that relaxations are related to the dynamic viscosity [19-22].

\section{CODE VALIDATION}

The performance of the using code via channel problem is established by comparing our predictions with the analytical solution [24] and other numerical results, namely those of Habchi and Acharya [5]. By taking into account the same hypotheses, the present results, displayed in Fig. 2, shows an excellent agreement with analytical solution and those of Habchi and Acharya as the maximum discrepancy is about $1 \%$.

(a)

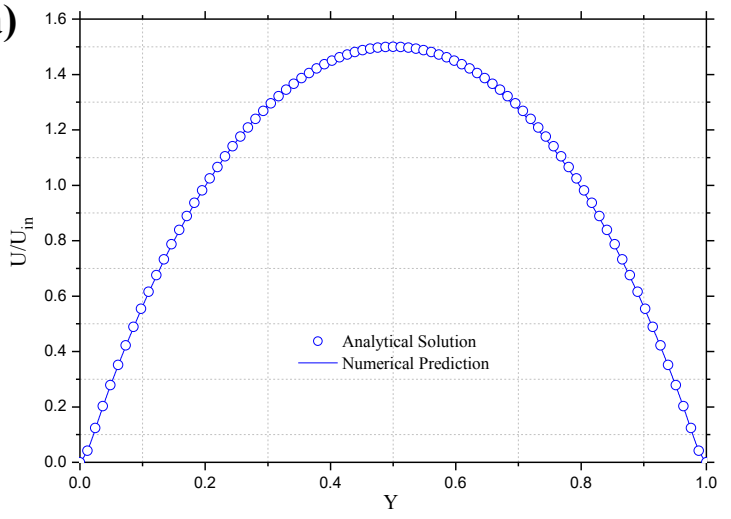

(b

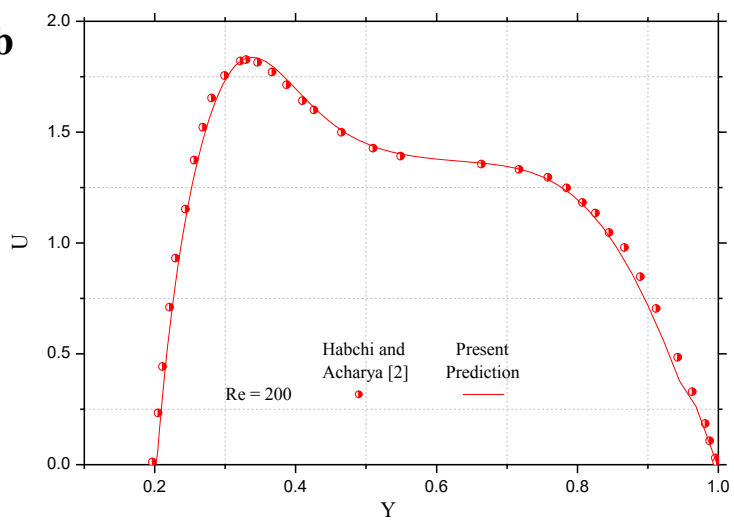

Fig. 2 Velocity profile, a comparison with analytic solution (a) and Habchi and Acharya [5] predictions (b).

\section{RESULTS \& DISCUSSION}

The presented results are generated for various dimensionless groups, such as the Reynolds number (10 $\leq \mathrm{Re} \leq 200)$ and the blocks' shape (Cylindrical/ Elliptic). The Prandtl number is fixed at 7.The predicted hydrodynamic fields' variables are presented through the Streamlines and the velocity profiles. The drop pressure profile of the studied cases is also represented in order to supply useful information about the influence of each parameter, quoted above, on the stability system.

Start our investigation by putting two cylindrical partitions within the channel the one next to the other (case 01). The Streamlines illustrated in Fig. 3 are obtained for various values of Reynolds number (Re) such as $10,50,100$ and 150 .

As we can see, the fluid motion within the channel is developed horizontally and parallel to the longitudinal direction. The increase in the Reynolds number, for a fixed distance between the cylinders raises a secondary eddies; which become stronger as long as Reynolds number increases. This phenomenon can be related to the longitudinal velocity in between the blocks, as shown Fig. 4, which is an increasing function of the Reynolds number. The critical value of Rayleigh number for the appearance of these mixed zones (i.e. the secondary eddies) is found equals to 100 .

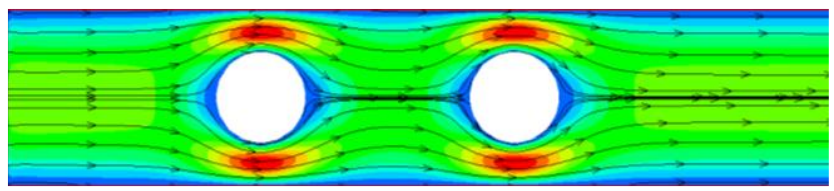

$(\operatorname{Re}=10)$

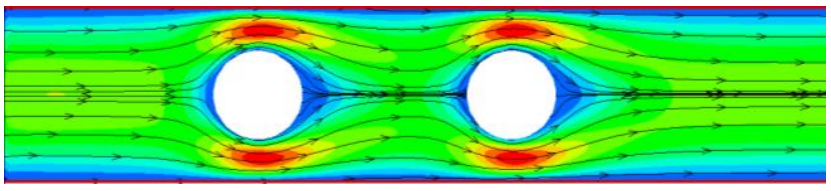

$(\operatorname{Re}=50)$

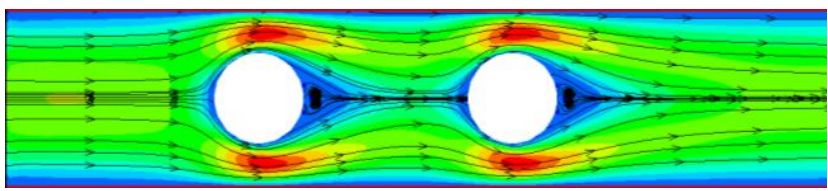

$(\operatorname{Re}=100)$

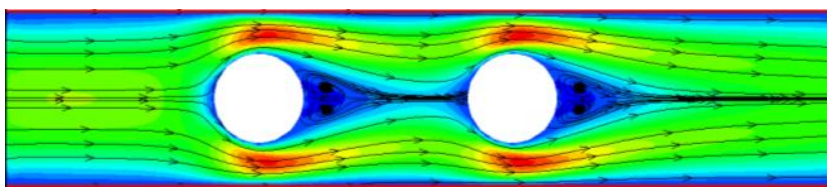

$(\operatorname{Re}=150)$

Fig. 3 Velocity contours of the Newtonian fluid for various values of Reynolds number (Case 01).

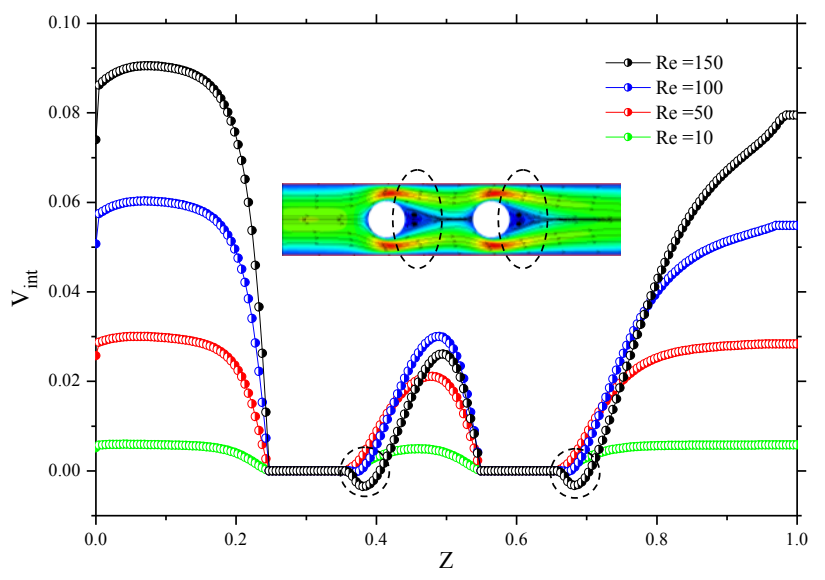

Fig. $4 V_{\text {int }}$ profiles in the mid-section plan of the channel ( $y=$ 0.5 ) for various values of Reynolds number (Case 1).

As long as the second case is concerned, Figs. 4 and 5 displays the Streamlines and the $\mathrm{V}_{\text {int }}$ of the Newtonian fluid and that, using an elliptic block's shape which mounted horizontally. As before, the impact of Reynolds number still observed. In other words, the fluid velocity is an increasing function of the latter as the fluid motion becomes stronger. Unlike the case before (i.e. Case 01), 
the horizontal arrangement of the elliptical blocks die out the secondary eddies within the channel. As this arrangement is suitable for a stable fluid' motion next each partition.

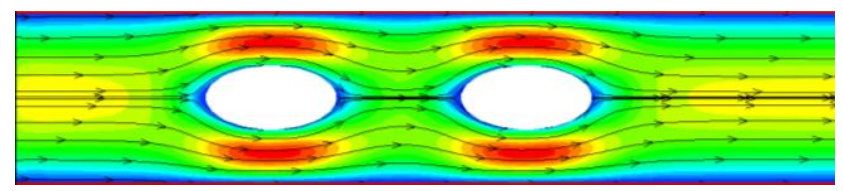

$(\operatorname{Re}=10)$

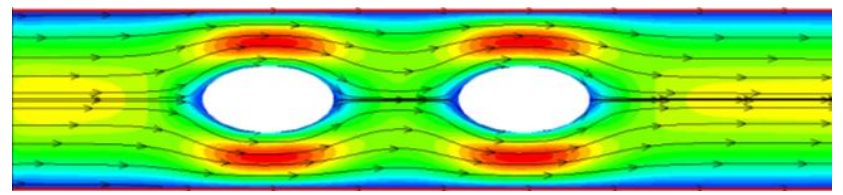

$(\operatorname{Re}=50)$

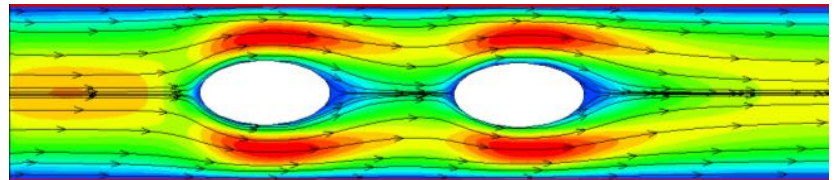

$(\operatorname{Re}=100)$

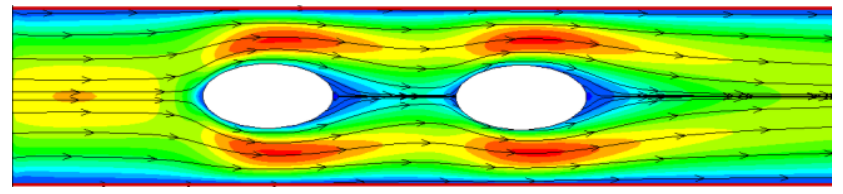

$(\operatorname{Re}=150)$

Fig. 5 Velocity contours of the Newtonian fluid for various values of Reynolds number (Case 02).

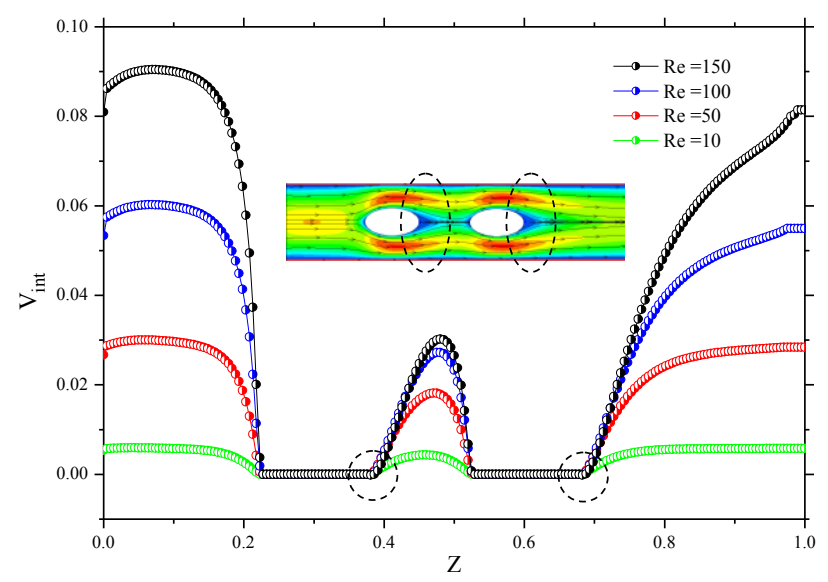

Fig. $6 \mathrm{~V}_{\text {int }}$ profiles in the mid-section plan of the channel $(y=0.5)$ for various values of Reynolds number (Case 2).

Regarding the vertical emplacement of the elliptic blocks, (which presented as our $3^{\text {rd }}$ case), Figs. 7 and 8 summarized the impact of Reynolds number on the fluid motion and its velocity, respectively. Unlike the previous cases, the presence of a vertical elliptic blocks light out the secondary eddies at a low Reynolds value, as $\mathrm{Re}=$ 50. These eddies becomes stronger as long as the Reynolds number increases. With $\mathrm{Re}=150$, the secondary eddies raised next the first blocks are found developed all along the distance in between the blocks.
The fluid motion within the horizontal channel is then so important.

Referred to Fig. 9, which displays the global pressure drop evolution of the investigated cases with respect Reynolds number and partitions' shape, respectively, using a cylindrical shape (case 01) promotes the global pressure drop into the rectangular channel, especially with a significant Reynolds value compared to the horizontal elliptic one; what makes the latter undesired for the convenience of practical applications.

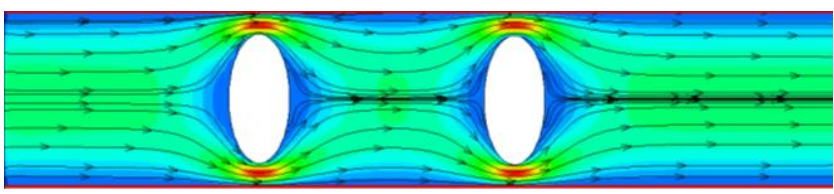

$(\mathrm{Re}=10)$

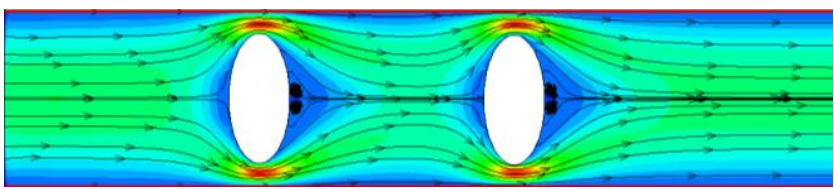

$(\operatorname{Re}=50)$

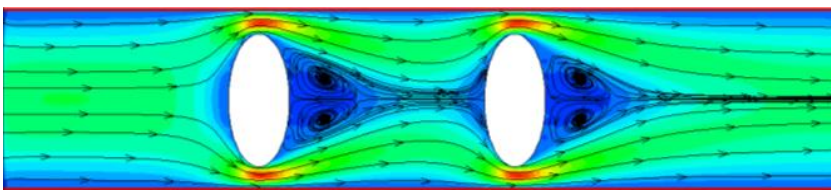

$(\operatorname{Re}=100)$

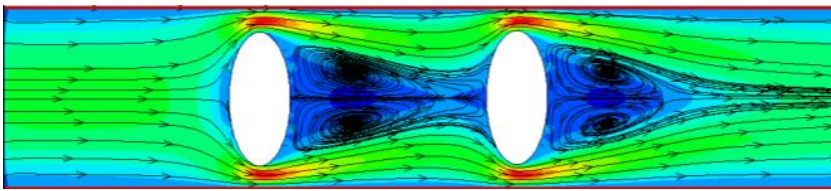

$(\operatorname{Re}=150)$

Fig. 7 Velocity contours of the Newtonian fluid for various values of Reynolds number (Case 3).

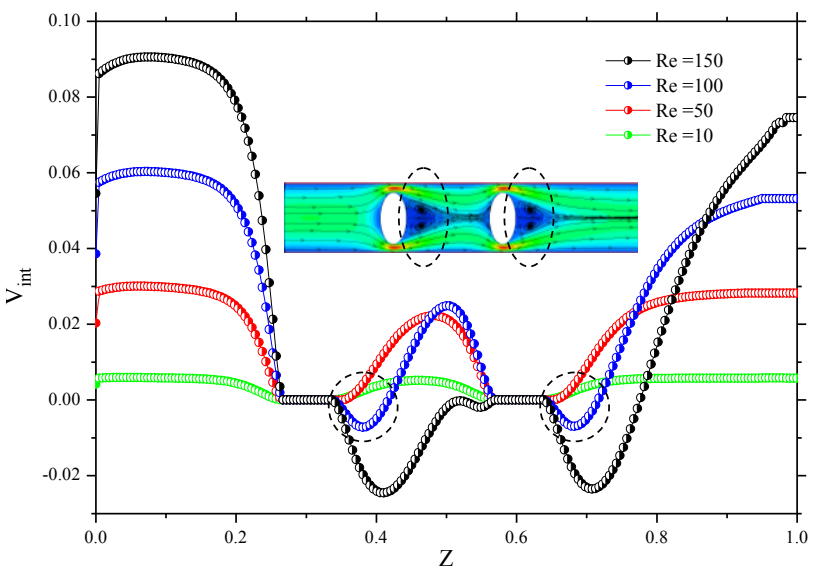

Fig. $8 \mathrm{~V}_{\text {int }}$ profiles in the mid-section plan of the channel $(y=0.5)$ for various values of Reynolds number (Case 3).

Yes of course, the vertical arrangement of the elliptic blocks makes the fluid mixture more important but unfortunately, the latter amplify the drop pressure to a dangerous level. 


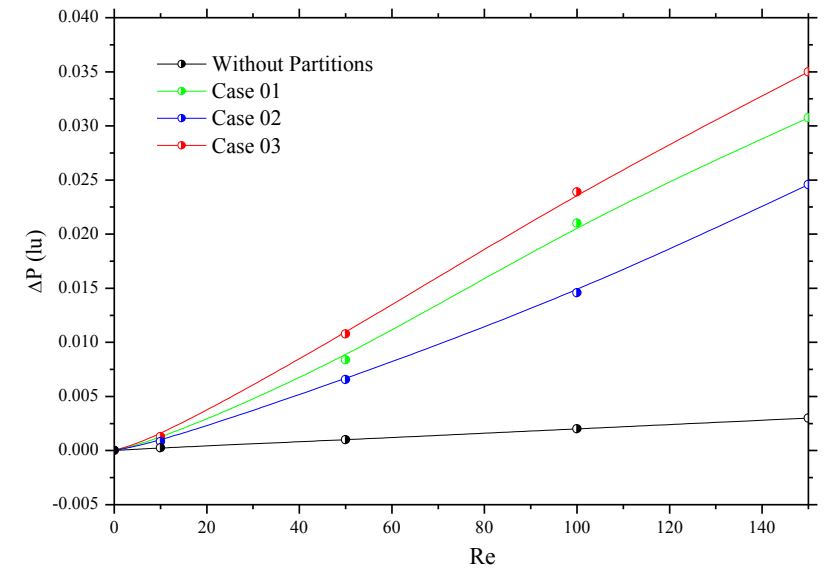

Fig. 9 Global pressure drop evolution with Reynolds numbers for the studied partitions' shapes. $\operatorname{Pr}=7$.

\section{CONCLUSION}

A numerical investigation of a Newtonian fluid flow within a partitioned rectangular channel was realized in this paper using the lattice-Boltzmann approach. Three cases are widely inspected: in the first one, two cylindrical blocks are mounted in the rectangular channel, the one next to the other. In the second case, horizontal elliptical blocks are used, when in the third, vertical elliptical blocks are taking place within the channel.

Regarding these cases, the fluid velocity is found to be an increasing function of the Reynolds number and seems to be severely affected by the blocks' shape.

Using a horizontal elliptic arrangement seems to be suitable for the global pressure drop diminution, when the vertical arrangement is desired to improve the mixing of the fluid medium, but still in dangerous manner.

Note that the present investigation doesn't present the mean heat and mass transfer, what provide guidance for future work.

\section{REFERENCES}

1. J.R. Koseff, R.L. Street, J. fluid Eng. 106, 21 (1984).

2. G. Barakos, and E. Mitsoulis. Int. J. Num. Methods Fluids.18, 695 (1994).

3. B. Calcagni; F. Marsili, M. Paroncini, Appl. Thermal Eng. 25, 2522 (2005).

4. R.Y. Jou, S.C. Tzeng, Int. Commun. Heat Mass Transfer, 33, 727 (2006).

5. S. Habchi, S. Acharya, Int. J. Heat Mass Transfer, 29, 1711 (1986).

6. H.W. Wu, S.W. Perng, Int. J. Heat Transf. 42, 1217 (1999).

7. M.H. Yong, R.H. Yeh, J.J. Hwang, Energy Conv. and Manag. 51, 1277 (2010).
8. J.C. Cheng, Y.L. Tsay, J. Heat Mass Transf. 42 (9), 843 (2006).

9. T.J. Young, K. Vafai, Int. J. Heat Mass Transf. 41, 3131 (1998).

10. S.Y. Kim, B.H. Kang, Int. J. Heat Mass Transf., 41, 625 (1998).

11. A. Boudiaf, F. Danane, Y. K. Benkahla, N. Labsi and A. Boutra, Mechanics \& Industry, 19, 210 (2018).

12. A. Boutra, K. Ragui, N. Labsi, R. Bennacer ,Y.K. Benkahla, Arabian Journal for Science and Engineering, 41: 1969(2016).

13. A. Boutra, K. Ragui, R. Bennacer, Y.K. Benkahla, Eur. Phys. j. appl. phys 74: 24612 (2016).

14. A. Bejan, John Wiley and Sons, Inc., (Hoboken, New jersey, 2004).

15. D. d'Humières, In: B.D. Shizgal and D.P. Weaver, Editors, Progr. Astro. Aero. 159, 450 (1992).

16. A. Boutra, Y.K. Benkahla, DE. Ameziani, R. Bennacer, Heat Transfer Research 48, 607 (2017).

17. Y.T. Yang, S.C. Chang, C.S. Chiou, Int. J. Heat Mass Transfer, 61, 543 (2012).

18. H. Yu, L. Luo, S.S. Girimaji, Comput. Fluids 35, 957 (2006).

19. A. Boutra, K. Ragui, R. Bennacer, Y.K. Benkahla, Energy Procedia, 139, 217 (2017).

20. A. Boutra, K. Ragui, N. Labsi, R. Y.K. Benkahla, Bennacer, Energy Procedia, 139, 173 (2017).

21. K. Bouarnouna, A. Boutra, K. Ragui, N. Labsi, Y.K. Benkahla, J. Statistical Phy. 126, 1 (2019).

22. L.S. Luo, Physical Rev. 62, 4982 (2000).

23. P. Lallemand, L.S. Luo, Physical Rev. 61, 6546 (2000).

24. A. Benzaoui, X. Nicolas, S. Xin, Num. Heat Transf. B. 48302 (2005). 